\title{
Metal biomarker mixtures and blood pressure in the United States: cross- sectional findings from the 1999-2006 National Health and Nutrition Examination Survey (NHANES)
}

Todd M. Everson ${ }^{1}$, Megan M. Niedzwiecki ${ }^{2}$, Daniell Toth ${ }^{3}$, Maria Tellez-Plaza ${ }^{4}$, Haoran Liư ${ }^{5}$, Dana B. Barr ${ }^{6}$ and Matthew O. Gribble ${ }^{1,7^{*}}$ (D)

\begin{abstract}
Background: The objective of this study was to identify conditional relationships between multiple metal biomarkers that predict systolic and diastolic blood pressure in the non-institutionalized United States adult population below the age of 60 .
\end{abstract}

Methods: We used inorganic exposure biomarker data and blood pressure data from three cycles (1999-2004) of the National Health and Nutrition Examination Survey (NHANES) to construct regression trees for blood pressure among adults ages 20-60 (adjusted for age, sex, body mass index, race, and smoking status) to identify predictors of systolic (SBP) and diastolic blood pressure (DBP). We also considered relationships among non-Hispanic black, Mexican-American, and white adults separately.

Results: The following metal exposure biomarkers were conditionally predictive of SBP and/or DBP in the full sample: antimony (Sb), barium (Ba), cadmium (Cd), cesium ( $\mathrm{Cs}$ ), lead (Pb), tungsten $(\mathrm{W})$ and molybdenum $(\mathrm{Mo})$. The highest average SBP $(>120 \mathrm{mmHg})$ was observed among those with low Sb $(\leq 0.21 \mu \mathrm{g} / \mathrm{dL})$ high $\mathrm{Cd}(>0.22 \mu \mathrm{g} / \mathrm{g}$ creatinine) and high $\mathrm{Pb}(>2.55 \mu \mathrm{g} / \mathrm{dL}$ ) biomarkers. Those with the highest average DBP had high urinary W levels $(>0.10 \mu \mathrm{g} / \mathrm{g}$ creatinine) in combination with either urinary Sb $>0.17 \mu \mathrm{g} / \mathrm{g}$ creatinine or those with urinary Sb $\leq$ $0.17 \mu \mathrm{g} / \mathrm{g}$ creatinine, but with high blood Pb levels (> $1.35 \mu \mathrm{g} / \mathrm{dL})$. Predictors differed by ethnicity, with $\mathrm{Cd}$ as the main predictor of SBP among non-Hispanic black adults, and Pb not selected by the algorithm as a predictor of SBP among non-Hispanic white adults.

(Continued on next page)

\footnotetext{
* Correspondence: matt.gribble@emory.edu

${ }^{1}$ Gangarosa Department of Environmental Health, Rollins School of Public

Health, Emory University, 1518 Clifton Road NE, Mailstop 1518-002-2BB,

Atlanta, GA 30322, USA

${ }^{7}$ Department of Epidemiology, Rollins School of Public Health, Emory

University, 1518 Clifton Road NE, Mailstop 1518-002-2BB, Atlanta, GA 30322,

USA

Full list of author information is available at the end of the article
}

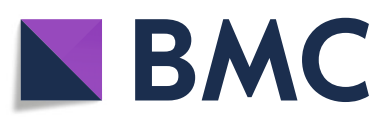

(C) The Author(s). 2021 Open Access This article is licensed under a Creative Commons Attribution 4.0 International License, which permits use, sharing, adaptation, distribution and reproduction in any medium or format, as long as you give appropriate credit to the original author(s) and the source, provide a link to the Creative Commons licence, and indicate if changes were made. The images or other third party material in this article are included in the article's Creative Commons licence, unless indicated otherwise in a credit line to the material. If material is not included in the article's Creative Commons licence and your intended use is not permitted by statutory regulation or exceeds the permitted use, you will need to obtain permission directly from the copyright holder. To view a copy of this licence, visit http://creativecommons.org/licenses/by/4.0/ The Creative Commons Public Domain Dedication waiver (http://creativecommons.org/publicdomain/zero/1.0/) applies to the data made available in this article, unless otherwise stated in a credit line to the data. 
(Continued from previous page)

Conclusions: Combinations of metal biomarkers have different apparent relationships with blood pressure. Additional research in toxicological experimental models and in epidemiological studies is warranted to evaluate the suggested possible toxicological interactions between $\mathrm{Sb}, \mathrm{Cd}$, and Pb; and between $\mathrm{W}$, Sb, and Pb; for cardiovascular (e.g., blood pressure) health. We also think future epidemiological research on inorganic exposure sets in relation to health outcomes like blood pressure might benefit from stratification by race and ethnicity.

Keywords: Mixtures, Risk assessment, Synergy, Antagonism, Survey statistics, cardiovascular epidemiology, Environmental epidemiology

Elevated blood pressure (BP) contributes greatly to cardiovascular disease morbidity and mortality [1]. In the Global Burden of Disease, Injuries, and Risk Factors study 2015, elevated systolic blood pressure (SBP) was identified as an enormously influential risk factor contributing to disability adjusted life-years worldwide [2]. Elevated BP is positively associated with risk for cardiometabolic diseases, even below the previously established thresholds for hypertension, which has led to lowering the recommended SBP and diastolic BP (DBP) thresholds for defining hypertension by $10 \mathrm{mmHg}$ each [3]. Thus, identifying opportunities to reduce exposure to determinants of higher BP is of substantial public health interest.

The literature examining joint associations between multiple metals and markers of cardiovascular health is limited, particularly in the context of large populationrepresentative samples. There are studies that have considered possible joint effects of metals and metalloids on blood pressure outcomes in the National Health and Nutrition Examination Survey (NHANES), for example zinc-and-copper [4] or mercury-and-selenium [5], but agnostic screens for higher-order interactions between metals for cardiovascular traits in representative population samples are rare. One study [6] used principal components to summarize complex patterns of exposure to multiple metals and relate those principal components to metabolic syndrome in NHANES 2011-2014; however, using principal components emphasizes the variation between people in exposures, irrespective of the health outcomes, and may identify exposure gradients that are different from the set of joint exposures most synergistically relevant for toxicity.

Another study [7] analyzing data from NHANES 2003-2014, applied machine learning approaches that did not directly allow for incorporation of survey design information, in order to generate summary variables (termed "Environmental Risk Scores") summarizing multiple metals predictive of an oxidative stress biomarker in the study sample; the Environmental Risk Score summary variables were then used as predictors in conventional survey regression analysis with cardiovascular outcomes.
The objective of this study was to investigate whether combinations of metals could predict SBP or DBP in NHANES, which collects rich data on biomarkers of environmental exposures in the US population, using regression trees-a popular data-driven method to identify the conditional effects of multiple exposures. Until recently, regression trees have been inappropriate for analysis of complex population-relevant surveys such as NHANES since traditional regression tree methods do not account for the clustering, stratification and weighting of complex survey designs. This study advances the methodology of population-scale environmental epidemiology by using survey-consistent regression trees to characterize conditional effects of multiple inorganic exposures on blood pressure in NHANES. We recognize that there may be systematic differences in exposure both to metals and to potential effect modifiers by race and ethnicity in the United States, and so in secondary analyses we fitted survey-consistent regression trees within race-ethnicity strata.

\section{Methods}

\section{Study population}

This study was performed using data obtained from NHANES, a nationally-representative cross-sectional survey of the non-institutionalized US population that is conducted by the Centers for Disease Control and Prevention $(\mathrm{CDC})$ on a continuous basis with data-released in two-year cycles. For this analysis, we pooled data from the 1999-2000, 2001-2002, and 2003-2004 survey cycles and restricted our sample to include participants $\geq 20$ years and $<60$ years of age who participated at mobile examination centers (MEC), had SBP or DBP measurements taken, and in whom barium (Ba), Cd, Co, Cs, molybdenum (Mo), Sb, thallium (Tl), and tungsten (W) had been measured in urine, and $\mathrm{Pb}$ had been measured in blood. We restricted to adults under age 60 because in that decade of age diastolic blood pressure stops increasing and instead begins to decrease [8], and so it is possible the mechanistic biology relevant to blood pressure could be different after that inflection point. Furthermore, since there is some emerging evidence that metabolic syndrome might decrease bone density $[9,10]$, 
and lead is accumulated in bone and released into blood as bone density decreases [11, 12], it seemed possible that inclusion of older participants with a higher prevalence of metabolic syndrome [13] in this data analysis could highlight reverse-causal associations driven by possible metabolic syndrome impacts on blood lead concentrations, complicating interpretation of the jointmetal associations. Participants with missing data for body mass index $(\mathrm{BMI})$ or smoking status $(n=33)$ were excluded. One primary sampling unit $(\mathrm{SDMVPSU}=3)$ had very few study participants $(n=32)$ and thus, these participants were pooled with another sampling unit (SDMVPSU $=1$ ) to stabilize model estimation. After pooling data across survey cycles and applying exclusions, our final analytic dataset consisted of 2413 individuals with complete data on metallic concentrations, SBP, DBP, age, sex, race, body mass index (BMI) and smoking status (Fig. 1). We did not correct the study analysis weights for missing data nonresponse so our results might be more comparable with other analyses of NHANES data.

\section{Systolic and diastolic blood pressure}

SBP and DBP were measured via standardized protocols $[14,15]$. Briefly, BP was measured in a sitting position after 5 min of rest via a calibrated mercury sphygmomanometer (Baumanometer ${ }^{\circ}$ ) which was fit to the bare right arm. Up to four measures of BP were obtained. If $\mathrm{BP}$ was only measured once, that measurement was used, whereas if multiple measures of BP were obtained, the first measure was excluded prior to calculating the average. Averages for systolic blood pressure (SBP) or diastolic blood pressure (DBP) that were recorded in the $\mathrm{CDC}$ dataset as zero were recoded as missing.

\section{Metals concentrations}

Blood and urine samples were collected from individuals that participated in the physical exams at MEC; samples were frozen until laboratory analyses could be performed. Urine creatinine was measured using an automatic colorimetric determination based on a modified Jaffe reaction while metals concentrations in urine and blood were measured using inductively coupled plasmamass spectrometry (ICP-MS) with a dynamic reaction cell to reduce interferences. Urinary cadmium concentrations were adjusted for molybdenum oxide interference [16]. Only the 2003-2004 survey cycle included an indicator variable for urinary and blood metal concentrations below the limits of detection (LOD), so data from this cycle were utilized to identify which metals

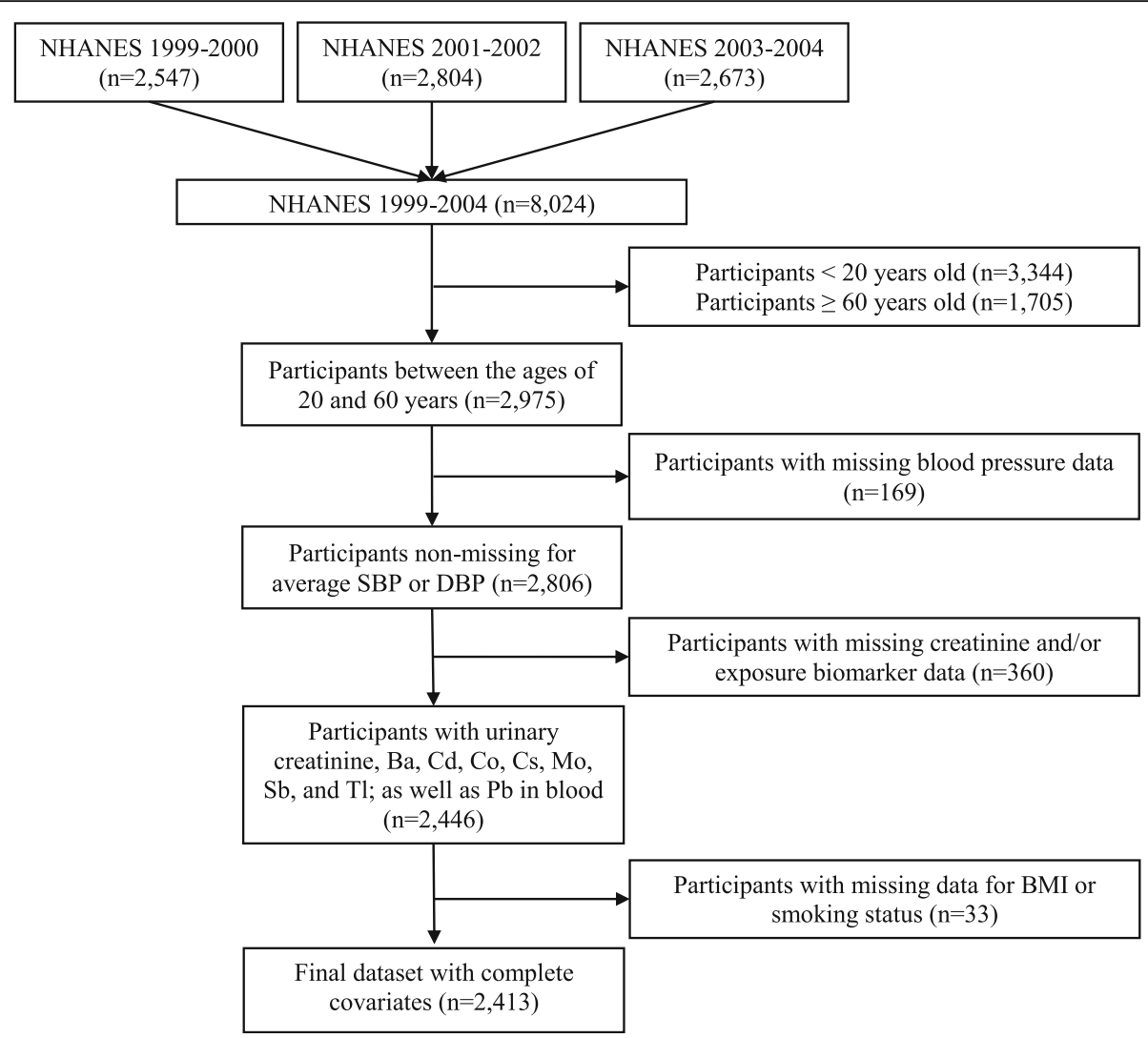

Fig. 1 Flow diagram of sample pooling, eligibility, missing data leading to exclusion and final sample used for this analysis 
had high proportions of samples below the LODs. Metals concentrations were detectable in $>80 \%$ of samples for all metals, with the exceptions of beryllium (Be) (0.82\%), platinum (Pt) (0.47\%), Sb (59.44\%), and W (78.32\%) (Supplemental Table 1); Pt and Be were excluded from this analysis because $>99 \%$ of values were below the limit of detection. For all other metals that were below the limit of detection, we utilized the imputed values reported by the $\mathrm{CDC}$, which were equal to the detection limit divided by the square root of two. All metal concentrations measured in urine were standardized for creatinine by dividing each metal by the grams of creatinine per liter of urine. For models in which metals were natural log-transformed, two urinary $\mathrm{Cd}$ concentrations that were reported as zero were recoded to the minimum nonzero reported concentrations in our sample $(0.00016 \mu \mathrm{g} / \mathrm{g}$ creatinine). Although $\mathrm{Pb}$ was measured in both blood and urine, we only included blood $\mathrm{Pb}$ concentrations in this analysis since this performs best for both high and low exposure levels [17]. Additionally, Cd was also measured in both blood and urine; we only included urinary $\mathrm{Cd}$ in this study since this is more representative of long-term exposure and body burden of Cd [18].

\section{Confounders and effect modifiers}

The potential influences of race and ethnicity, sex, age, body mass index (BMI), and smoking status were controlled for within the survey linear models. We considered that age and BMI might not exhibit linear relationships with SBP or DBP and used loess curves to examine the nature of those associations. The association between both SBP or DBP with age was best approximated by a quadratic function; thus, age and age ${ }^{2}$ were included in the model while the associations with BMI were approximately linear. Race/ ethnicity was also considered as a potential effect modifier, and therefore regression trees were also estimated separately within race/ethnicity strata. Tobacco smoke can be a source of exposure for many of these toxic metals [19] and can influence cardiovascular health through other mechanisms [20]. Therefore, tobacco consumption behavior (i.e., current smoker, former smoker, never smoker) was of interest as a confounder of the relationship between joint metal exposures and blood pressure. Participants that reported fewer than 100 cigarettes in their lifetime were coded as 'never smokers'; those that reported smoking at least 100 cigarettes and that they now smoke cigarettes 'every day' or 'some days' were coded as 'current smokers'; and as 'former smokers' if they reported that they now smoke 'not at all'.

\section{Statistical analyses}

To account for the pooling of three different survey cycles, we calculated a 6-year survey weight per the CDC's recommendation, multiplying the four-year heavy metal subsample weight (WTSHM4YR) by two thirds for participants sampled during 1999-2000 and 2001-2002, while multiplying the two-year subsample weight (WTSA2YR) by one third for participants sampled during 2003-2004. These weights were not further recalibrated to the subset of complete cases used in our analysis.

Statistical analyses were conducted in $\mathrm{R}$ version 3.4.4. We first examined the independent relationship of each individual creatinine-corrected metal, natural logtransformed, with SBP or DBP, while adjusting for age, $\mathrm{age}^{2}$, race, sex, BMI, and smoking status, using survey linear regression methods from the survey package [21] and computed Wald-type 95\% confidence intervals.

To explore non-linear relationships and potential high-order interactions between metals, we modeled sample-weighted and survey-design corrected regression trees via the recursive partitioning for modelling survey data (rpms) method [22, 23]. This method applies a recursive partitioning algorithm to a set of variables to generate a binary regression tree for a continuous outcome. Binary splits are identified using a permutation test that permutes the weighted residuals, $w_{i}\left(y_{i}-\mu\right)$ within clusters and the estimated cluster effect among clusters, thus accounting for the complex survey design on the expected distribution of $Y$ under the null, where $\mathrm{Y}$ is independent of the groups defined by the binary split. For each variable, this test is performed many times, each at the optimal cut-point to account for the fact that the data was observed before selecting splits. Among the variables that are below the designated $p$ value ( $p$-value $<0.05$ ), the variables and the cut-point that leads to the partition with the largest test-statistic is selected to split the data.

Within each node of the tree, the rpms algorithm also estimates the parameters of a survey regression model specified by (SBP or DBP $\sim$ age $+\mathrm{age}^{2}+\mathrm{BMI}+\mathrm{sex}+$ race + smoking status), while accounting for the survey design (weights, clusters, and strata), producing surveydesign consistent regression models for each node conditional on the binary splits. Predicted means of Y (SBP or DBP in our case) and standard errors are estimated within each node. The recursive partitioning uses the residualized SBP and DBP values within the child nodes until none of the partitioning tests yield permutation $p$ values $<0.05$, or when a node reaches a specified size limit. We implemented rpms with 2500 permutations and restricted the minimum terminal node size to $10 \%$ of our sample size, meaning that the regression tree would not produce end nodes containing fewer than 
$10 \%$ of the unweighted sample. In additional models, we stratified by self-reported non-Hispanic white adults, Mexican American adults, and non-Hispanic black adults to estimate demographically specific regression trees. For each of these demographically specific trees, predicted SBP or DBP were adjusted for age, age ${ }^{2}, \mathrm{BMI}$, sex, and smoking status.

\section{Results}

Combining three NHANES survey cycles (1999-2004), we examined how multiple metals were jointly associated with SBP or DBP among the 2413 individuals aged 20-59 years with complete data on SBP, DBP, biomarkers of internal dose of $\mathrm{Ba}, \mathrm{Cd}, \mathrm{Co}, \mathrm{Cs}, \mathrm{Mo}, \mathrm{Pb}, \mathrm{Sb}$, $\mathrm{W}$, and $\mathrm{Tl}$ concentrations in urine had been measured ( $\mathrm{Pb}$ was measured in blood), as well as age, sex, race, $\mathrm{BMI}$, and smoking status. The metals $\mathrm{Ba}, \mathrm{Cd}, \mathrm{Co}, \mathrm{Cs}$, $\mathrm{Mo}$, and $\mathrm{Tl}$ were detectable in $>80 \%$ of urine samples and $\mathrm{Pb}$ was detectable in $>80 \%$ of blood samples, per the LODs from the 2003-2004 cycle (Supplemental Table 1); metals that were below the detection limits for $>50 \%$ of samples were excluded from this study. The weighted concentrations of each metal overall, and within race/ethnicity specific strata are presented in Table 1.

We first examined the correlation structure of the 9 metals. While most metals only exhibited modest, weak, or no correlations, there were a few notable moderate and strong pairwise correlations: cesium (Cs) and thallium ( $\mathrm{Tl}$ ) were strongly correlated ( $\mathrm{cor}=0.59, p$ value $<2 \mathrm{E}-16)$, while barium $(\mathrm{Ba})$ and cobalt $(\mathrm{Co})$, and antimony $(\mathrm{Sb})$ and tungsten (W) were moderately correlated (cor $=0.41 \& 0.29$, respectively). We then examined the individual associations between metals with SBP or DBP by regressing BP $(\mathrm{mm} \mathrm{Hg})$ on the log-transformed metal concentration while adjusting for age, $\mathrm{age}^{2}$, sex, race, BMI and smoking status. We observed numerous associations via this individual screening. Higher concentrations of $\mathrm{Ba}, \mathrm{Sb}, \mathrm{W}$, and $\mathrm{Pb}$ were associated with higher SBP, and similarly, though with smaller magnitudes of effect, for DBP; additionally, increasing concentrations of Cs and Mo were associated with lower DBP (Table 2). We then used multiple regression models for both SBP and DBP with all 9 metals included as independent variables and adjusting for the same confounders as in the above models. While adjusting for the concentrations of all other metals, $\mathrm{Ba}\left(\beta_{1}=1.0,95 \% \mathrm{CI}=\right.$ $0.17,1.84)$ and $\mathrm{Sb}\left(\beta_{1}=1.57,95 \% \mathrm{CI}=0.19,2.95\right)$ were associated with elevated SBP, while Mo $\left(\beta_{1}=-1.42,95 \%\right.$ $\mathrm{CI}=-2.69,-0.15)$ was associated lower SBP. Additionally, while adjusting for all other metals, $\mathrm{W}\left(\beta_{1}=0.65\right.$, $95 \% \mathrm{CI}=0.03,1.27)$ was associated with elevated DBP and Mo $\left(\beta_{1}=-1.44,95 \% \mathrm{CI}=-2.10,-0.77\right)$ was associated with lower DBP.

We then applied the rpms algorithm to examine conditional relationships of metals biomarker combinations with SBP or DBP, while adjusting for age, age ${ }^{2}$, race, sex, $\mathrm{BMI}$, and smoking status. This method identified $\mathrm{Ba}, \mathrm{Cd}$,

Table 1 Weighted medians and IQRs for metals concentrations in urine (per gram of creatinine) and blood, overall and stratified by race and ethnicity

\begin{tabular}{|c|c|c|c|c|c|}
\hline Median (IQR) & All Samples & Non-Hispanic White Adults & Mexican- American Adults & Non-Hispanic black Adults & Other \\
\hline Urine ( $\mu \mathrm{g} / \mathrm{g}$ creatinine) & $N=2413$ & $N=1166$ & & & \\
\hline $\mathrm{Ba}$ & $\begin{array}{l}1.33 \\
(0.75,2.31)\end{array}$ & $\begin{array}{l}1.45 \\
(0.84,2.54)\end{array}$ & $\begin{array}{l}0.99 \\
(0.63,2.00)\end{array}$ & $\begin{array}{l}0.90 \\
(0.43,1.45)\end{array}$ & $\begin{array}{l}1.33 \\
(0.77,2.32)\end{array}$ \\
\hline $\mathrm{Cd}$ & $\begin{array}{l}0.23 \\
(0.13,0.40)\end{array}$ & $\begin{array}{l}0.23 \\
(0.13,0.40)\end{array}$ & $\begin{array}{l}0.19 \\
(0.12,0.31)\end{array}$ & $\begin{array}{l}0.23 \\
(0.13,0.41)\end{array}$ & $\begin{array}{l}0.24 \\
(0.16,0.42)\end{array}$ \\
\hline Co & $\begin{array}{l}0.28 \\
(0.19,0.42)\end{array}$ & $\begin{array}{l}0.29 \\
(0.20,0.42)\end{array}$ & $\begin{array}{l}0.29 \\
(0.20,0.45)\end{array}$ & $\begin{array}{l}0.23 \\
(0.16,0.37)\end{array}$ & $\begin{array}{l}0.27 \\
(0.20,0.42)\end{array}$ \\
\hline Cs & $\begin{array}{l}4.24 \\
(3.23,5.67)\end{array}$ & $\begin{array}{l}4.43 \\
(3.44,5.90)\end{array}$ & $\begin{array}{l}4.12 \\
(3.09,5.22)\end{array}$ & $\begin{array}{l}3.20 \\
(2.48,4.08)\end{array}$ & $\begin{array}{l}4.19 \\
(2.92,6.00)\end{array}$ \\
\hline Mo & $\begin{array}{l}37.3 \\
(25.4,52.4)\end{array}$ & $\begin{array}{l}37.6 \\
(25.6,52.3)\end{array}$ & $\begin{array}{l}40.6 \\
(29.9,54.6)\end{array}$ & $\begin{array}{l}31.7 \\
(21.4,44.9)\end{array}$ & $\begin{array}{l}39.5 \\
(25.1,58.4)\end{array}$ \\
\hline $\mathrm{Sb}$ & $\begin{array}{l}0.10 \\
(0.06,0.15)\end{array}$ & $\begin{array}{l}0.10 \\
(0.06,0.16)\end{array}$ & $\begin{array}{l}0.09 \\
(0.07,0.14)\end{array}$ & $\begin{array}{l}0.08 \\
(0.06,0.12)\end{array}$ & $\begin{array}{l}0.09 \\
(0.06,0.14)\end{array}$ \\
\hline $\mathrm{Tl}$ & $\begin{array}{l}0.15 \\
(0.11,0.20)\end{array}$ & $\begin{array}{l}0.15 \\
(0.11,0.21)\end{array}$ & $\begin{array}{l}0.14 \\
(0.11,0.18)\end{array}$ & $\begin{array}{l}0.12 \\
(0.09,0.17)\end{array}$ & $\begin{array}{l}0.16 \\
(0.11,0.21)\end{array}$ \\
\hline W & $\begin{array}{l}0.06 \\
(0.03,0.11)\end{array}$ & $\begin{array}{l}0.06 \\
(0.04,0.11)\end{array}$ & $\begin{array}{l}0.07 \\
(0.04,0.11)\end{array}$ & $\begin{array}{l}0.05 \\
(0.03,0.09)\end{array}$ & $\begin{array}{l}0.06 \\
(0.03,0.11)\end{array}$ \\
\hline \multicolumn{6}{|l|}{ Blood } \\
\hline $\mathrm{Pb}(\mu \mathrm{g} / \mathrm{dL})$ & $\begin{array}{l}1.5 \\
(1,2.2)\end{array}$ & $\begin{array}{l}1.4 \\
(1,2.2)\end{array}$ & $\begin{array}{l}1.7 \\
(1,2.7)\end{array}$ & $\begin{array}{l}1.5 \\
(1.1,2.4)\end{array}$ & $\begin{array}{l}1.6 \\
(1,2.3)\end{array}$ \\
\hline
\end{tabular}

IQR: Inter-quartile range, Ba: barium, Cd: cadmium, Co: cobalt, Cs: cesium, Mo: molybdenum, Pb: lead, Sb: antimony, Tl: thallium, and W: tungsten. 
Table 2 Estimated change in SBP $(\mathrm{mm} \mathrm{Hg})$ and DBP $(\mathrm{mm} \mathrm{Hg})$ corresponding to a log increase in metals concentrations, adjusted for age, age ${ }^{2}$, race, sex, BMl, and smoking status; parameters estimated via survey linear regression. Models were fit separately for each metal

\begin{tabular}{|c|c|c|c|c|c|c|c|c|}
\hline \multirow[b]{2}{*}{ Metals } & \multicolumn{4}{|c|}{$\mathrm{SBP}(\mathrm{mm} \mathrm{Hg})$} & \multicolumn{4}{|c|}{$\mathrm{DBP}(\mathrm{mm} \mathrm{Hg})$} \\
\hline & $\overline{\beta_{1}}$ & SE & P-value & $95 \% \mathrm{Cl}$ & $\beta_{1}$ & SE & P-value & $95 \% \mathrm{Cl}$ \\
\hline \multicolumn{9}{|l|}{ Urine } \\
\hline $\mathrm{Ba}$ & 1.20 & 0.41 & 0.0065 & $(0.38,2.00)$ & 0.47 & 0.31 & 0.1428 & $(-0.1,1.07)$ \\
\hline $\mathrm{Cd}$ & -0.23 & 0.56 & 0.6876 & $(-1.3,0.86)$ & 0.14 & 0.32 & 0.6706 & $(-0.4,0.76)$ \\
\hline Co & 0.99 & 0.58 & 0.0977 & $(-0.1,2.13)$ & 0.08 & 0.33 & 0.8042 & $(-0.5,0.73)$ \\
\hline Cs & -1.13 & 0.88 & 0.2083 & $(-2.8,0.59)$ & -1.49 & 0.67 & 0.0321 & $(-2.7,-0.1)$ \\
\hline Mo & -1.06 & 0.60 & 0.0876 & $(-2.2,0.12)$ & -1.34 & 0.32 & 0.0002 & $(-1.9,-0.7)$ \\
\hline $\mathrm{Sb}$ & 2.09 & 0.60 & 0.0013 & $(0.92,3.25)$ & 1.04 & 0.49 & 0.0421 & $(0.07,2.01)$ \\
\hline $\mathrm{Tl}$ & -0.26 & 0.98 & 0.7939 & $(-2.1,1.66)$ & -1.18 & 0.59 & 0.0516 & $(-2.3,-0.0)$ \\
\hline W & 1.05 & 0.43 & 0.0207 & $(0.20,1.89)$ & 0.62 & 0.31 & 0.0568 & $(0.00,1.23)$ \\
\hline \multicolumn{9}{|l|}{ Blood } \\
\hline $\mathrm{Pb}$ & 1.39 & 0.68 & 0.0478 & $(0.06,2.71)$ & 0.78 & 0.49 & 0.1197 & $(-0.1,1.73)$ \\
\hline
\end{tabular}

SBP: systolic blood pressure, DBP: diastolic blood pressure, BMI: body mass index, $\beta_{1}$ : slope of the regression line, SE: standard error, Cl: confidence interval, Ba: barium, Cd: cadmium, Co: cobalt, Cs: cesium, Mo: molybdenum, Pb: lead, Sb: antimony, TI: thallium, and W: tungsten.

Table 3 Estimated mean SBP ( $\mathrm{mm} \mathrm{Hg}$ ) within each node produced from binary partitions from metals concentrations, adjusted for age, age ${ }^{2}$, race, sex, BMI, and smoking status; partitions can be linked to the SBP tree via lower case roman numerals (i-vii), and child nodes are classified as left $(\mathrm{L})$ or right $(\mathrm{R})$, relative to their position in the tree, for each partition

\begin{tabular}{llllll}
\hline Partition & Node & End Node & Splits & N & Mean SBP \\
\hline NA & Root & No & NA & 2413 & 119.05 \\
i & $\mathrm{L}$ & No & Sb $\leq 0.21$ & 2095 & 118.59 \\
& $\mathrm{R}$ & Yes & $\mathrm{Sb}>0.21$ & 318 & 122.08 \\
ii & $\mathrm{L}$ & No & $\mathrm{Cd} \leq 0.22$ & 1047 & 117.34 \\
& $\mathrm{R}$ & No & $\mathrm{Cd}>0.22$ & 1048 & 119.74 \\
iii & $\mathrm{L}$ & Yes & $\mathrm{Cs} \leq 2.75$ & 243 & 119.87 \\
& $\mathrm{R}$ & No & $\mathrm{Cs}>2.75$ & 804 & 116.53 \\
iv & $\mathrm{L}$ & No & $\mathrm{Pb} \leq 2.55$ & 782 & 117.82 \\
& $\mathrm{R}$ & Yes & $\mathrm{Pb}>2.55$ & 266 & 125.83 \\
v & $\mathrm{L}$ & Yes & $\mathrm{W} \leq 0.07$ & 432 & 115.56 \\
& $\mathrm{R}$ & Yes & $\mathrm{W}>0.07$ & 372 & 117.52 \\
vi & $\mathrm{L}$ & No & $\mathrm{W} \leq 0.09$ & 536 & 119.59 \\
& $\mathrm{R}$ & Yes & $\mathrm{W}>0.09$ & 246 & 113.65 \\
vii & $\mathrm{L}$ & Yes & $\mathrm{Ba} \leq 1.23$ & 292 & 119.50 \\
& $\mathrm{R}$ & Yes & $\mathrm{Ba}>1.23$ & 244 & 119.41
\end{tabular}

SBP: systolic blood pressure, Ba: urinary barium ( $\mu \mathrm{g} / \mathrm{g}$ creatinine), Cd: urinary cadmium ( $\mu \mathrm{g} / \mathrm{g}$ creatinine), Cs: urinary cesium ( $\mu \mathrm{g} / \mathrm{g}$ creatinine), Pb: blood lead $(\mu \mathrm{g} / \mathrm{dL})$, Sb: urinary antimony $(\mu \mathrm{g} / \mathrm{g}$ creatinine), W: urinary tungsten $(\mu \mathrm{g} / \mathrm{g}$ creatinine).
$\mathrm{Cs}, \mathrm{Pb}, \mathrm{Sb}$, and $\mathrm{W}$ as potential predictors of SBP (Fig. 2 \& Table 3) and $\mathrm{Cs}, \mathrm{Mo}, \mathrm{Pb}, \mathrm{Sb}$, and $\mathrm{W}$ as the predictors of DBP (Fig. 3 \& Table 4). Sb was selected in the root node for the SBP tree, and those with high urinary $\mathrm{Sb}$ (> $0.21 \mu \mathrm{g} / \mathrm{g}$ creatinine) had the second highest SBP overall $(122.08 \mathrm{mmHg})$. Those with the highest estimated SBP $(125.83 \mathrm{mmHg})$ had $\mathrm{Sb} \leq 0.21 \mu \mathrm{g} / \mathrm{g}$ creatinine, but with high urinary $\mathrm{Cd}(>0.22 \mu \mathrm{g} / \mathrm{g}$ creatinine $)$ and high blood $\mathrm{Pb}(>2.55 \mu \mathrm{g} / \mathrm{dL})$.

We also fitted trees separately for non-Hispanic black adults, Mexican American adults, and non-Hispanic white adults. Among non-Hispanic black adults (Supplemental Fig. 1), Cd was selected as the root node (> $0.36 \mu \mathrm{g} / \mathrm{g}$ creatinine) for SBP. Among non-Hispanic black adults, higher $\mathrm{Pb}$ levels were associated with higher SBP, conditional on concentrations of $\mathrm{Cd}$ and Mo. Among Mexican American adults (Supplemental Fig. 2), Cs was selected as the root node for SBP, and the combination of high Cs (>3.90 $\mu \mathrm{g} / \mathrm{g}$ creatinine) with high blood $\mathrm{Pb}(2.45 \mu \mathrm{g} / \mathrm{dL})$ was associated with the highest average SBP (125.26 mmHg). Among non-Hispanic white adults (Supplemental Fig. 3), the combination of high W $(>0.10 \mu \mathrm{g} / \mathrm{g}$ creatinine) with high $\mathrm{Sb}(>0.21 \mu \mathrm{g} / \mathrm{g}$ creatinine) was associated with the highest average SBP $(122.05 \mathrm{mmHg})$. Interestingly, blood $\mathrm{Pb}$ was not selected as a risk factor for elevated SBP among non-Hispanic white adults, however it was a predictor of SBP among Mexican American adults (Supplemental Fig. 2) and non-Hispanic black adults (Supplemental Fig. 1).

The patterns were slightly different for DBP. Among non-Hispanic black adults (Supplemental Fig. 4), higher $\mathrm{Pb}(>1.65 \mu \mathrm{g} / \mathrm{dL})$ was a predictor of high DBP only among those with $\mathrm{Cs} \leq 2.36 \mu \mathrm{g} / \mathrm{g}$ creatinine. The DBP 


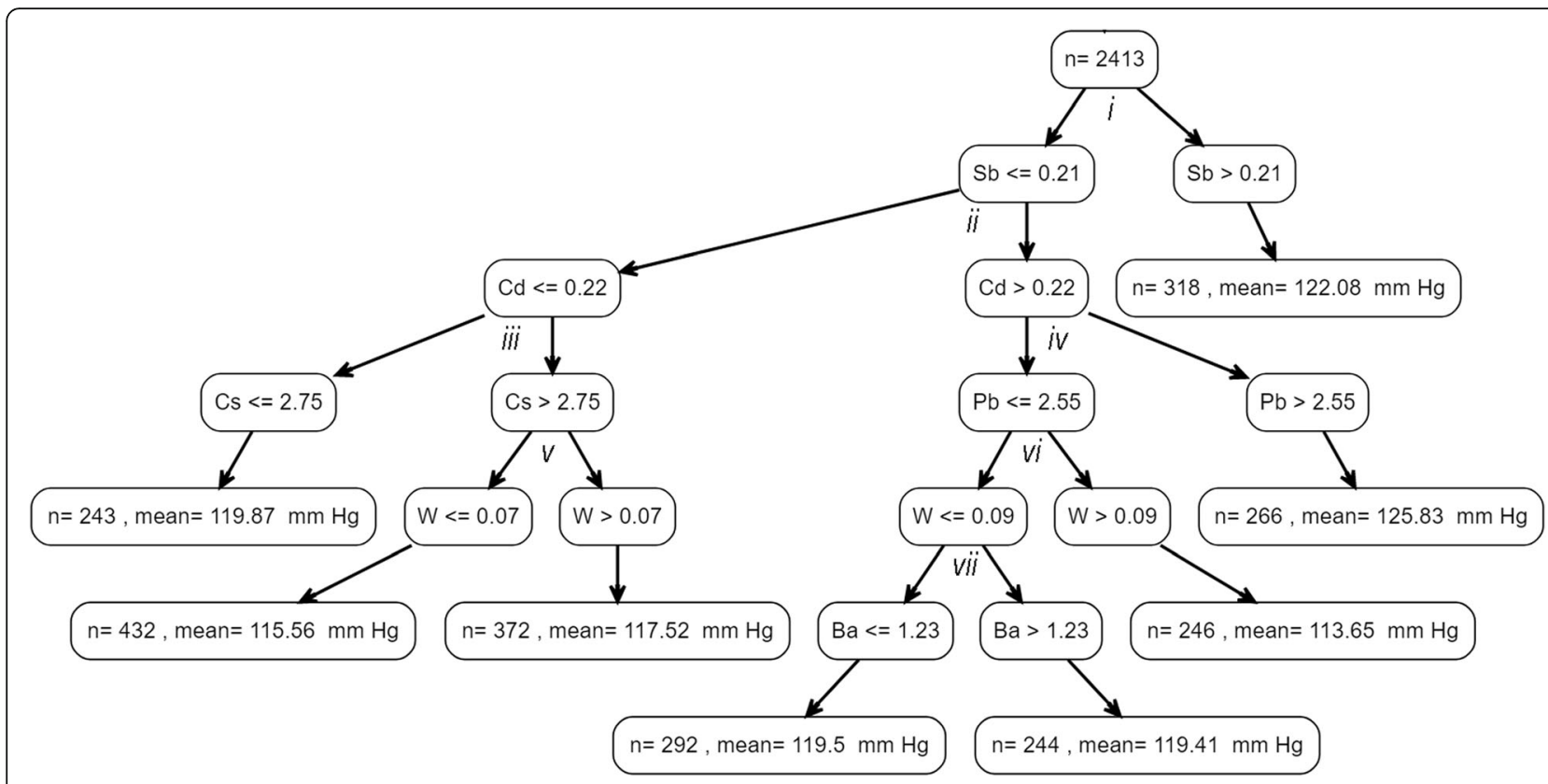

Fig. 2 Regression tree for estimated average SBP as a product of metals biomarkers in urine and blood while adjusting for age, age ${ }^{2}$, sex, race, $\mathrm{BMI}$, and smoking status; partitions are labeled (i-vii) so that the difference in SBP that is acheived with each binary split can be observed in Table 3. Concentrations of metal biomarkers are either $\mu \mathrm{g} / \mathrm{dL}$ blood ( $\mathrm{Pb}$ only) or $\mu \mathrm{g} / \mathrm{g}$ creatinine (all other metals in urine)

tree for Mexican American adults (Supplemental Fig. 5) identified Cs and W as predictors, in which lower levels of these metals were associated with lower DBP, conditional on $\mathrm{Tl}$ concentrations. Among non-Hispanic white adults (Supplemental Fig. 6) Pb was selected as the root node.

Finally, we tested whether the regression trees for SBP and DBP that were trained on three NHANES cycles
(1999-2000, 2001-2002, and 2003-2004), could be informative about SBP and/or DBP in an independent NHANES dataset (the 2005-2006 cycle). For this analyses, we predicted SBP and DBP for each participant in the 2005-2006 cycle with complete biomarker, blood pressure, and covariate data while applying the same exclusion criteria $(n=950)$ using the primary regression trees that were trained on the 1999-2004 cycles, then

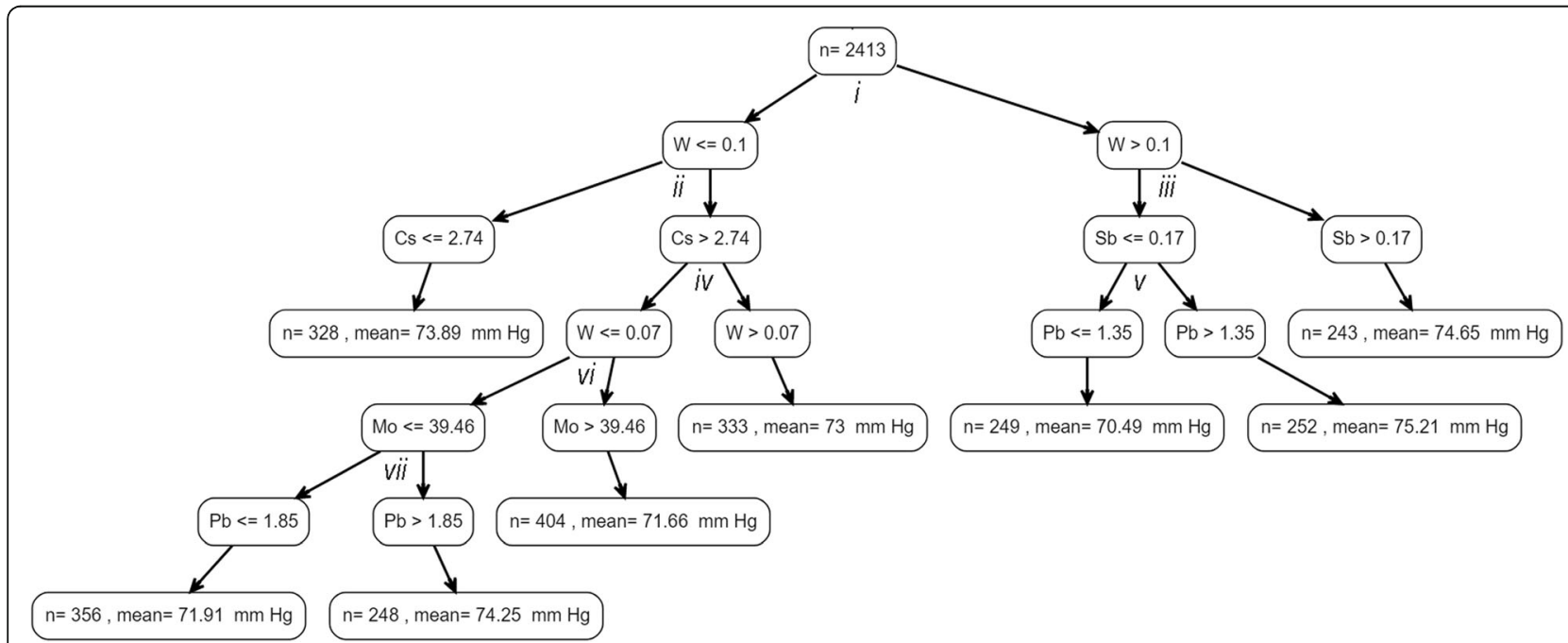

Fig. 3 Regression tree for estimated average DBP as a product of metals biomarkers in urine and blood while adjusting for age, age ${ }^{2}$, sex, race, BMI, and smoking status; partitions are labeled (i-vii) so that the difference in DBP that is acheived with each binary split can be observed in Table 4. Urine metal biomarkers are corrected for grams of creatinine. Concentrations of metal biomarkers are either $\mu \mathrm{g} / \mathrm{dL}$ blood (Pb only) or $\mu \mathrm{g} / \mathrm{g}$ creatinine (all other metals in urine) 
Table 4 Estimated mean DBP $(\mathrm{mm} \mathrm{Hg})$ within each node produced from binary partitions from metals concentrations, adjusted for age, age ${ }^{2}$, race, sex, BMl, and smoking status; partitions can be linked to the DBP tree via lower case roman numerals (i-vii), and child nodes are classified as left $(\mathrm{L})$ or right (R) for each partition

\begin{tabular}{llllll}
\hline Partition & Node & End Node & Splits & N & Mean DBP \\
\hline NA & Root & No & NA & 2413 & 73.06 \\
i & L & No & W $\leq 0.1$ & 1669 & 72.85 \\
& $\mathrm{R}$ & No & W $>0.1$ & 744 & 73.48 \\
ii & L & Yes & Cs $\leq 2.74$ & 328 & 73.89 \\
& $\mathrm{R}$ & No & $\mathrm{Cs}>2.74$ & 1341 & 72.59 \\
iii & $\mathrm{L}$ & No & $\mathrm{Sb} \leq 0.17$ & 501 & 72.83 \\
& $\mathrm{R}$ & Yes & $\mathrm{Sb}>0.17$ & 243 & 74.65 \\
iv & $\mathrm{L}$ & No & $\mathrm{W} \leq 0.07$ & 1008 & 72.43 \\
& $\mathrm{R}$ & Yes & $\mathrm{W}>0.07$ & 333 & 73.00 \\
v & $\mathrm{L}$ & Yes & $\mathrm{Pb} \leq 1.35$ & 249 & 70.49 \\
& $\mathrm{R}$ & Yes & $\mathrm{Pb}>1.35$ & 252 & 75.21 \\
vi & $\mathrm{L}$ & No & $\mathrm{Mo} \leq 39.46$ & 604 & 72.96 \\
& $\mathrm{R}$ & Yes & $\mathrm{Mo}>39.46$ & 404 & 71.66 \\
vii & $\mathrm{L}$ & Yes & $\mathrm{Pb} \leq 1.85$ & 356 & 71.91 \\
& $\mathrm{R}$ & Yes & $\mathrm{Pb}>1.85$ & 248 & 74.25 \\
\hline
\end{tabular}

DBP: diastolic blood pressure, Cs: urinary cesium ( $\mu \mathrm{g} / \mathrm{g}$ creatinine), Mo: urinary molybdenum ( $\mu \mathrm{g} / \mathrm{g}$ creatinine), Pb: blood lead $(\mu \mathrm{g} / \mathrm{dL}), \mathrm{Sb}$ : urinary antimony $(\mu \mathrm{g} / \mathrm{g}$ creatinine), W: urinary tungsten $(\mu \mathrm{g} / \mathrm{g}$ creatinine).

compared predicted versus reported blood pressure with Spearman's correlations. We found that that predicted SBP and DBP were moderately positively correlated with reported SBP and DBP $\left(\mathrm{rho}_{\mathrm{SBP}}=0.41\right.$ and $\mathrm{rho}_{\mathrm{DBP}}=0.37$, $p$-values $<2.2 \mathrm{E}-16)$ in these independent data.

\section{Discussion}

Our study found that increased biomarker concentrations of $\mathrm{Ba}, \mathrm{Sb}, \mathrm{W}$ and $\mathrm{Pb}$ exposure were associated with elevated $\mathrm{SBP}, \mathrm{Sb}$ was also associated with elevated DBP, and biomarkers of $\mathrm{Cs}$ and Mo were inversely associated with DBP in linear regression models fit for each metal separately. While controlling for all metal concentrations simultaneously, four metals (Ba, Sb, W, and $\mathrm{Mo}$ ) were associated with SBP and DBP. When we applied the regression tree approach that accommodates complex joint effects of multiple metal exposures, many of the metals predictive of SBP or DBP in this analysis had substantial overlap with the set identified in the more traditional regression approach. Those with higher concentrations of $\mathrm{Sb}, \mathrm{Cd}, \mathrm{W}$, and $\mathrm{Pb}$ tended to have higher predicted SBP, while those with higher Cs and Mo tended to have lower SBP and DBP.

The metal that was most strongly associated with SBP $\mathrm{Sb})$ in linear models was also selected by the rpms algorithm as the metal on which to partition the root node for the SBP tree, suggesting that $\mathrm{Sb}$ is an important overall predictor of SBP at the population level. However, the regression tree approach provided additional insights regarding the joint relationships between metals and blood pressure. For instance, at the population-level, it appears as though $\mathrm{Sb}, \mathrm{Cd}, \mathrm{Pb}$, and their potential interactions may be particularly important for elevated systolic blood pressure. We found that the only subgroups with average SBP estimated to be greater than $120 \mathrm{mmHg}$, were those with either $\mathrm{Sb}>0.21 \mu \mathrm{g} / \mathrm{g}$ creatinine, or those with $\mathrm{Sb} \leq 0.21 \mu \mathrm{g} / \mathrm{g}$ creatinine but in combination with $\mathrm{Cd}>0.22 \mu \mathrm{g} / \mathrm{g}$ creatinine and with blood $\mathrm{Pb}>2.55 \mu \mathrm{g} / \mathrm{dL}$. Additionally, the highest estimated DBP was among those with a metal biomarker profile of $\mathrm{W}>0.10 \mu \mathrm{g} / \mathrm{g}$ creatinine, $\mathrm{Sb} \leq 0.17 \mu \mathrm{g} / \mathrm{g}$ creatinine, and blood $\mathrm{Pb}>1.35 \mu \mathrm{g} / \mathrm{dL}$. Although, $\mathrm{Cd}$ and $\mathrm{Pb}$ have previously been characterized as risk factors for higher blood pressure, there is less evidence regarding the potential impacts of $\mathrm{W}$ and $\mathrm{Sb}$ [24], and none explicitly examining their interactions. Our findings suggest that further research is needed to better characterize the impacts of $\mathrm{W}$ and $\mathrm{Sb}$ on cardiovascular health, and their potential interactions with $\mathrm{Cd}$ and $\mathrm{Pb}$ concentrations.

Our analysis also suggested that the metallic determinants of SBP and DBP differ across demographic subgroups of the US population, though there are also some similarities. For instance, blood $\mathrm{Pb}$ levels were identified as a predictor of elevated SBP in both non-Hispanic black adults and Mexican American adults, and of elevated DBP among both non-Hispanic white adults and non-Hispanic black adults. However, the conditional relationships between $\mathrm{Pb}$ and other metals for their impacts on BP differed within each of these sub-groups. Similarly, W was included in all SBP and DBP trees, except for the DBP tree for non-Hispanic black adults, and was often selected included within the same branch of the tree as $\mathrm{Pb}$. Antimony $(\mathrm{Sb})$, which was the root node for the population-level SBP tree, appears to primarily affect SBP among non-Hispanic white adults, while $\mathrm{Cd}$ appears to be a particularly important predictor of elevated SBP among non-Hispanic black adults. The unique metallic risk factors and conditional relationships within these racial and ethnic subgroups could be due to different sources of exposure. For example: a major source of cadmium exposure is smoking [25], and non-Hispanic black Americans are more likely to smoke menthol-flavored cigarettes than white or Mexican-American adults [26], so the uniquely significant relationships of blood pressure to cadmium in non-Hispanic black adults might be reflecting exposures related to menthol cigarettes and menthol cigarette smoking-related behaviors. A limitation of our study is that we only considered the differences in 
conditional inference trees by race/ethnicity and did not account for possible differences in tree structure according to socioeconomic position independent of race and ethnicity. Both race/ethnicity and socioeconomic position play important roles in shaping exposure to environmental hazards in the United States [2729].

Our study provides significant and novel insights into how environmental exposure to metals relate to blood pressure in the United States population. The most notable results from our study were the identification of thresholds and joint relationships between $\mathrm{W}, \mathrm{Sb}, \mathrm{Cd}$, and $\mathrm{Pb}$ as determinants of elevated SBP and DBP. Exposure to $\mathrm{Pb}$ and $\mathrm{Cd}$ in the US population has declined since the 1980s, and a recent study found that the declining rates of cardiovascular diseases are likely related, in part, to these reductions in exposure to $\mathrm{Pb}$ and $\mathrm{Cd}$ [30]. However, since $\mathrm{Pb}$ and $\mathrm{Cd}$ have been often related to cardiovascular outcomes and elevated blood pressure [31-33], if they are toxic even at low doses [34], then further reductions in exposure to these two metals might benefit public health.

Our results suggest that higher $\mathrm{Sb}$ concentrations were associated with higher SBP, and that co-exposure to $\mathrm{Cd}$ and $\mathrm{Pb}$, among those with lower $\mathrm{Sb}$ concentration, may have elevated SBP. We also found that higher W concentrations were associated with higher DBP, and our observed associations with $\mathrm{Sb}$ and $\mathrm{Pb}$ on $\mathrm{DBP}$ were conditional on W concentrations. Although numerous epidemiologic studies have observed relationships between $\mathrm{Cd}$ and $\mathrm{Pb}$ with elevated blood pressure [24], fewer studies have examined the potential cardiovascular impacts of Sb or W. However, elevated Sb exposure has been associated with increased prevalence of heart disease and heart disease mortality in the US population between 1999 and 2010 [35] and associated with high BP, defined as $\geq 140$ or $90 \mathrm{mmHg}$ for SBP or DBP, respectively, in the 2011-2012 NHANES survey cycle [36]. W and Sb were also associated in NHANES 1999-2006 with a composite outcome of cardiovascular and cerebrovascular disease [37]. Our findings complement these studies, indicating that $\mathrm{Sb}$ and $\mathrm{W}$ may be predictors of elevated BP. Unlike these past studies, we found that $\mathrm{W}$ and $\mathrm{Sb}$ may also modify the relationships between $\mathrm{Pb}$ and $\mathrm{Cd}$ with BP.

Our findings also suggest that higher concentrations of Cs and Mo were associated with lower BP (Cs: lower SBP, Cs and Mo: lower DBP). Previous studies examining the impacts of Cs and Mo on BP have been limited in number. Our current results support findings from a previous analysis of NHANES survey cycle data from 1999 to 2012, which found that Cs was associated with lower SBP and DBP [38], and results from a small epidemiological study of particulate matter (PM) constituents, which found negative associations between Mo and SBP/DBP [39]. Two studies in rat models also support that exposure to Cs [40] and Mo [41] may reduce BP. However, results from other studies have yielded different conclusions: two NHANES analyses (2009-2012 and 2011-2012 cycles) identified positive associations of Cs and Mo with high BP [36, 42], and a study of aging men with metabolic syndrome found no significant Spearman correlation between urinary Mo and SBP or DBP [43]. Additional studies are warranted to examine the relationships of Sb and Mo with BP.

This paper illustrates a novel data analysis approach that can be applied to other studies of how multiple exposures may associate with health outcomes, while leveraging the rich exposure data in large surveys. Though our analysis focused on a panel metals, this approach can complement the growing interest in environment-wide and exposuremixture studies [44] to include exploration of how jointassociations between multiple co-exposures and components of mixtures can impact health. However, there are some limitations to this approach that cannot be overlooked. First, as with any modeling effort, the quality of results is dependent on the strength of the input data. Regression trees are entirely data-driven approaches that have the potential to overfit, meaning that the prediction tree may explain more of the variance in the supplied data than it would in an independent dataset. There are numerous tree-based ensemble methods designed to reduce overfitting by resampling both predictors and observations to produce multiple regression or classification trees, most notably random forests [45] and gradient-boosted trees [46]. These methods produce more accurate predictions, but interpretation of the actual relationships between predictors is not possible. Ensemble methods for regression trees have not yet been developed that are suitable for complex survey data analysis, and this is an area of interest for future methods development.

\section{Conclusions}

In summary, in this application of rpms to data from adults age 20-60 in the United States, we identified numerous relationships between metal exposure biomarkers and SBP or DBP, with the most notable combinations being the potential interactions between $\mathrm{W}, \mathrm{Sb}, \mathrm{Cd}$ and $\mathrm{Pb}$. These findings add to the current body of evidence that $\mathrm{Cd}$ and $\mathrm{Pb}$ exposures are risk factors for elevated blood pressure, while providing additional evidence for an association between $\mathrm{Sb}$ and $\mathrm{W}$ with elevated $\mathrm{BP}$, which may also modify the cardiovascular impacts of $\mathrm{Pb}$ and $\mathrm{Cd}$. We also found that racial and ethnic sub-groups of the US population may have different metallic determinants of SBP and DBP, with high Sb being particularly relevant among non-Hispanic white adults and $\mathrm{Cd}$ being especially pertinent for BP among non-Hispanic black adults. The 
rpms framework can be used to model additional sets of exposures in future studies, advancing understanding of how the environment in gestalt contributes to health and disease in specific (formally surveyed) human populations.

\section{Supplementary Information}

The online version contains supplementary material available at https://doi. org/10.1186/s12940-021-00695-1

\section{Additional file 1: Supplemental Fig. 1. Among non-Hispanic black} adults: regression tree for estimated SBP as a product of metals biomarkers in urine and blood while adjusting age, age ${ }^{2}$, sex, BMl and smoking status. Urine metal biomarkers are corrected for grams of creatinine. Concentrations of metal biomarkers are either $\mu \mathrm{g} / \mathrm{dL}$ blood ( $\mathrm{Pb}$ only) or $\mu \mathrm{g} / \mathrm{g}$ creatinine (all other metals in urine).

Additional file 2: Supplemental Fig. 2. Among Mexican-American adults: regression tree for estimated SBP as a product of metals biomarkers in urine and blood while adjusting age, age ${ }^{2}$, sex, BMl and smoking status. Urine metal biomarkers are corrected for grams of creatinine. Concentrations of metal biomarkers are either $\mu \mathrm{g} / \mathrm{dL}$ blood ( $\mathrm{Pb}$ only) or $\mu \mathrm{g} / \mathrm{g}$ creatinine (all other metals in urine).

Additional file 3: Supplemental Fig. 3 Among non-Hispanic white adults: regression trees for estimated SBP as a function of metals biomarkers in urine and blood while adjusting age, age ${ }^{2}$, sex, BMl and smoking status. Concentrations of metal biomarkers are either $\mu \mathrm{g} / \mathrm{dL}$ blood ( $\mathrm{Pb}$ only) or $\mu \mathrm{g} / \mathrm{g}$ creatinine (all other metals in urine).

Additional file 4: Supplemental Fig. 4. Among non-Hispanic black adults: regression tree for estimated DBP as a function of metals biomarkers in urine and blood while adjusting age, $\mathrm{age}^{2}$, sex, BMl and smoking status. Concentrations of metal biomarkers are either $\mu \mathrm{g} / \mathrm{dL}$ blood ( $\mathrm{Pb}$ only) or $\mu \mathrm{g} / \mathrm{g}$ creatinine (all other metals in urine).

Additional file 5: Supplemental Fig. 5. Among Mexican-American adults: regression tree for estimated DBP as a function of metals biomarkers in urine and blood while adjusting age, age ${ }^{2}$, sex, BMl and smoking status within strata of Mexican American adults. Concentrations of metal biomarkers are either $\mu \mathrm{g} / \mathrm{dL}$ blood (Pb only) or $\mu \mathrm{g} / \mathrm{g}$ creatinine (all other metals in urine).

Additional file 6: Supplemental Fig. 6. Among non-Hispanic white adults: regression tree for estimated DBP as a function of metals biomarkers in urine and blood while adjusting age, age ${ }^{2}$, sex, BMI and smoking status. Concentrations of metal biomarkers are either $\mu \mathrm{g} / \mathrm{dL}$ blood ( $\mathrm{Pb}$ only) or $\mu \mathrm{g} / \mathrm{g}$ creatinine (all other metals in urine).

Additional file 7: Supplemental Table 1. Proportions of metals concentrations with reported values that were above the limits of detection from the 2003-2004 cycle ( $n=852)$.

Additional file 8: Analysis Scripts and Data.

\section{Authors' contributions}

TME, MMN, and MOG conceived the study. MMN was primarily responsible for data management, and TME for implementing the data analysis, with support from $\mathrm{HL}$ and statistical supervision from DT and MOG. MTP and DDB were involved in the interpretation of findings.

\section{Funding}

This work was supported in part by the HERCULES Exposome Research Center funded by the National Institute of Environmental Health Sciences (P30 ES019776).

\section{Availability of data and materials}

This work uses publicly available datasets, and our code for accessing and analyzing these data is provided in the Supplement.

\section{Ethics approval and consent to participate}

As a secondary data analysis of publicly available deidentified data, this study is not considered Human Subjects Research.

\section{Consent for publication}

All authors approved the final version of the manuscript.

\section{Competing interests}

The authors declare that they have no actual or potential competing interests.

\section{Author details}

${ }^{1}$ Gangarosa Department of Environmental Health, Rollins School of Public Health, Emory University, 1518 Clifton Road NE, Mailstop 1518-002-2BB, Atlanta, GA 30322, USA. ²Department of Environmental Medicine \& Public Health, Icahn School of Medicine at Mount Sinai, New York, NY, USA. ${ }^{3}$ U.S. Bureau of Labor Statistics, Office of Survey Methods Research, D. C, Washington, USA. ${ }^{4}$ Biomedical Research Institute INCLIVA, Valencia, Spain ${ }^{5}$ Department of Biostatistics and Bioinformatics, Rollins School of Public Health, Emory University, Atlanta, GA, USA. 'aboratory for Exposure Assessment and Development for Environmental Research, Department of Environmental Health, Rollins School of Public Health, Emory University, Atlanta, GA 30322, USA. 'Department of Epidemiology, Rollins School of Public Health, Emory University, 1518 Clifton Road NE, Mailstop 1518-002-2BB, Atlanta, GA 30322, USA.

Received: 11 August 2020 Accepted: 18 January 2021 Published online: 14 February 2021

\section{References}

1. Benjamin EJ, Blaha MJ, Chiuve SE, Cushman M, Das SR, Deo R, de Ferranti SD, Floyd J, Fornage M, Gillespie C, et al. Heart disease and stroke Statistics2017 update: a report from the American Heart Association. Circulation. 2017;135(10):e146-603.

2. Global, regional, and national comparative risk assessment of 79 behavioural, environmental and occupational, and metabolic risks or clusters of risks, 1990-2015: A systematic analysis for the global burden of disease study 2015. Lancet 2016, 388(10053):1659-1724.

3. Whelton PK, Carey RM, Aronow WS, Casey DE Jr, Collins KJ, Dennison Himmelfarb C, DePalma SM, Gidding S, Jamerson KA, Jones DW, et al. 2017 ACC/AHA/AAPA/ABC/ACPM/AGS/APhA/ASH/ASPC/NMA/PCNA guideline for the prevention, detection, evaluation, and Management of High Blood Pressure in adults: executive summary: a report of the American College of Cardiology/American Heart Association task force on clinical practice guidelines. Hypertension. 2018;71(6):1269-324.

4. Yao J, Hu P, Zhang D. Associations between copper and zinc and risk of hypertension in US adults. Biol Trace Elem Res. 2018;186(2):346-53.

5. Park SK, Lee S, Basu N, Franzblau A. Associations of blood and urinary mercury with hypertension in U.S. adults: the NHANES 2003-2006. Environ Res. 2013;123:25-32.

6. Bulka CM, Persky WW, Daviglus ML, Durazo-Arvizu RA, Argos M. Multiple metal exposures and metabolic syndrome: a cross-sectional analysis of the National Health and nutrition examination survey 2011-2014. Environ Res. 2019:168:397-405

7. Park SK, Zhao Z, Mukherjee B. Construction of environmental risk score beyond standard linear models using machine learning methods: application to metal mixtures, oxidative stress and cardiovascular disease in NHANES. Environ Health. 2017;16(1):102

8. Franklin SS. Ageing and hypertension: the assessment of blood pressure indices in predicting coronary heart disease. J Hypertens Suppl. 1999;17(5): S29-36.

9. Eckstein N, Buchmann N, Demuth I, Steinhagen-Thiessen E, Nikolov J, Spira D, Eckardt R, Norman K. Association between metabolic syndrome and bone mineral density--data from the Berlin aging study II (BASE-II). Gerontology. 2016;62(3):337-44.

10. Alhazidou E, Pergialiotis V, Panagopoulos P, Chrelias C, Hatziagelaki E, Papantoniou N, Trakakis E. The impact of the metabolic syndrome on bone mass density: a prospective case control study. Horm Mol Biol Clin Investig. 2017:33(3).

11. Machida M, Sun SJ, Oguma E, Kayama F. High bone matrix turnover predicts blood levels of lead among perimenopausal women. Environ Res. 2009;109(7):880-6.

12. Silbergeld EK, Schwartz J, Mahaffey K. Lead and osteoporosis: mobilization of lead from bone in postmenopausal women. Environ Res. 1988:47(1):7994. 
13. Aguilar M, Bhuket $T$, Torres $S$, Liu B, Wong RJ. Prevalence of the metabolic syndrome in the United States, 2003-2012. JAMA. 2015;313(19):1973-4.

14. National Center for Health Statistics. 2002. National Health and Nutrition Examination Survey 1999-2000. Blood Pressure Section of the Physician's Examination. https://wwwn.cdc.gov/nchs/nhanes/1999-2000/BPX.htm. Accessed 01/13/2021.

15. National Center for Health Statistics. 2004. National Health and Nutrition Examination Survey 2001-2002. Blood Pressure Section of the Physician's Examination. https://wwwn.cdc.gov/nchs/nhanes/2001-2002/BPX_B.htm. Accessed 01/13/2021.

16. Jarrett JM, Xiao G, Caldwell KL, Henahan D, Shakirova G, Jones RL. Eliminating molybdenum oxide interference in urine cadmium biomonitoring using ICP-DRC-MS. J Anal Atom Spectrom. 2008;23(7):962-7.

17. Sommar JN, Hedmer M, Lundh T, Nilsson L, Skerfving S, Bergdahl IA. Investigation of lead concentrations in whole blood, plasma and urine as biomarkers for biological monitoring of lead exposure. J Expo Sci Environ Epidemiol. 2014;24(1):51-7.

18. Adams SV, Newcomb PA. Cadmium blood and urine concentrations as measures of exposure: NHANES 1999-2010. J Expo Sci Environ Epidemiol. 2014;24(2):163-70

19. Caruso RV, O'Connor RJ, Stephens WE, Cummings KM, Fong GT. Toxic metal concentrations in cigarettes obtained from U.S. smokers in 2009: Results from the international tobacco control (ITC) United States survey cohort. Int J Environ Res Public Health 2013. 11(1):202-17.

20. Mainali P, Pant S, Rodriguez AP, Deshmukh A, Mehta JL. Tobacco and cardiovascular health. Cardiovasc Toxicol. 2015;15(2):107-16.

21. Lumley T. Analysis of complex survey samples. J Stat Softw. 2004;9(1):1-19.

22. Toth D Package 'rpms'. 2017; version 0.2.1. https://cran.r-project.org/web/ packages/rpms/vignettes/rpms_2018_01_22.pdf. 01/03/2021.

23. Toth $D$, Eltinge JL. Building consistent regression trees from complex sample data. J Am Stat Assoc. 2011;106(496):1626-36.

24. Nigra AE, Ruiz-Hernandez A, Redon J, Navas-Acien A, Tellez-Plaza M. Environmental metals and cardiovascular disease in adults: a systematic review beyond Lead and cadmium. Curr Environ Health Rep. 2016;3(4):41633.

25. Aoki Y, Yee J, Mortensen ME. Blood cadmium by race/hispanic origin: the role of smoking. Environ Res. 2017;155:193-8.

26. Jones MR, Apelberg BJ, Tellez-Plaza M, Samet JM, Navas-Acien A. Menthol cigarettes, race/ethnicity, and biomarkers of tobacco use in U.S. adults: the 1999-2010 National Health and nutrition examination survey (NHANES). Cancer Epidemiol Biomarkers Prev. 2013;22(2):224-32.

27. Salazar DJ, Clauson S, Abel TD, Clauson A. Race, income, and environmental inequality in the U.S. states, 1990-2014. Soc Sci Quart. 2019;100(3):592-603.

28. Mikati I, Benson AF, Luben TJ, Sacks JD, Richmond-Bryant J. Disparities in distribution of particulate matter emission sources by race and poverty status. Am J Public Health. 2018;108(4):480-5.

29. Boyce JK, Zwickl K, Ash M. Measuring environmental inequality. Ecol Econ. 2016;124:114-23.

30. Ruiz-Hernandez A, Navas-Acien A, Pastor-Barriuso R, Crainiceanu CM, Redon J, Guallar E, Tellez-Plaza M. Declining exposures to lead and cadmium contribute to explaining the reduction of cardiovascular mortality in the US population, 1988-2004. Int J Epidemiol. 2017;46(6):1903-12.

31. Gallagher CM, Meliker JR. Blood and urine cadmium, blood pressure, and hypertension: a systematic review and meta-analysis. Environ Health Perspect. 2010;118(12):1676-84.

32. Chowdhury R, Ramond A, O'Keeffe LM, Shahzad S, Kunutsor SK, Muka T, Gregson J, Willeit P, Warnakula S, Khan H, et al. Environmental toxic metal contaminants and risk of cardiovascular disease: systematic review and meta-analysis. BMJ. 2018;362:k3310.

33. Navas-Acien A, Guallar E, Silbergeld EK, Rothenberg SJ. Lead exposure and cardiovascular disease--a systematic review. Environ Health Perspect. 2007; 115(3):472-82.

34. Scinicariello F, Abadin HG, Murray HE. Association of low-level blood lead and blood pressure in NHANES 1999-2006. Environ Res. 2011;111(8):1249-57.

35. Guo J, Su L, Zhao X, Xu Z, Chen G. Relationships between urinary antimony levels and both mortalities and prevalence of cancers and heart diseases in general US population, NHANES 1999-2010. Sci Total Environ. 2016;571:45260.

36. Shiue I. Higher urinary heavy metal, phthalate, and arsenic but not parabens concentrations in people with high blood pressure, U.S. NHANES, 2011 2012. Int J Environ Res Public Health. 2014;11(6):5989-99.
37. Agarwal S, Zaman T, Tuzcu EM, Kapadia SR. Heavy metals and cardiovascular disease: results from the National Health and nutrition examination survey (NHANES) 1999-2006. Angiology. 2011;62(5):422-9.

38. McGinnis DP, Brownstein JS, Patel CJ. Environment-Wide Association Study of Blood Pressure in the National Health and Nutrition Examination Survey (1999-2012). Sci Rep. 2016;(6):30373.

39. Wu S, Deng F, Huang J, Wang H, Shima M, Wang X, Qin Y, Zheng C, Wei H, Hao $Y$, et al. Blood pressure changes and chemical constituents of particulate air pollution: results from the healthy volunteer natural relocation (HVNR) study. Environ Health Perspect. 2013;121(1):66-72.

40. Guéguen Y, Lestaevel P, Grandcolas L, Baudelin C, Grison S, Jourdain JR, Gourmelon P, Souidi M. Chronic contamination of rats with 137 cesium radionuclide: impact on the cardiovascular system. Cardiovasc Toxicol. 2008; 8(1):33-40.

41. Peredo HA, Andrade V, Donoso AS, Lee HJ, Puyó AM. Sodium molybdate prevents hypertension and vascular prostanoid imbalance in fructoseoverloaded rats. Auton Autacoid Pharmacol. 2013;33(3-4):43-8.

42. Shiue I, Hristova K. Higher urinary heavy metal, phthalate and arsenic concentrations accounted for 3-19\% of the population attributable risk for high blood pressure: US NHANES, 2009-2012. Hypertens Res. 2014;37(12): 1075-81.

43. Rotter I, Kosik-Bogacka D, Dołęgowska B, Safranow K, Lubkowska A, Laszczyńska M. Relationship between the concentrations of heavy metals and bioelements in aging men with metabolic syndrome. Int J Environ Res Public Health. 2015;12(4):3944-61.

44. Patel CJ. Analytic complexity and challenges in identifying mixtures of exposures associated with phenotypes in the Exposome era. Curr Epidemiol Rep. 2017:4(1):22-30.

45. Breiman L. Random forests. Mach Learn. 2001;45(1):5-32.

46. Friedman $\mathrm{JH}$. Greedy function approximation: a gradient boosting machine. Ann Stat. 2001:29(5):1189-232.

\section{Publisher's Note}

Springer Nature remains neutral with regard to jurisdictional claims in published maps and institutional affiliations.
Ready to submit your research? Choose BMC and benefit from:

- fast, convenient online submission

- thorough peer review by experienced researchers in your field

- rapid publication on acceptance

- support for research data, including large and complex data types

- gold Open Access which fosters wider collaboration and increased citations

- maximum visibility for your research: over $100 \mathrm{M}$ website views per year

At BMC, research is always in progress.

Learn more biomedcentral.com/submissions 